\title{
A FORMAÇÃO DO SUJEITO MODERNO ATRAVÉS DA EDUCAÇÃO
}

BASTOS, Manoel de Jesus ${ }^{1}$

BASTOS, Manoel de Jesus. A Formação do Sujeito Moderno Através da Educação. Revista Científica Multidisciplinar Núcleo do Conhecimento. Ano 02, Ed. 01, Vol. 14, pp. 31-38 Janeiro de 2017. ISSN:2448-0959

\section{RESUMO}

O presente trabalho aborda assuntos pertinentes ao sujeito moderno, fragmentado pelo fenômeno globalização e influenciado pelas transformações desnorteadoras e insensatas do sistema capitalista. $O$ individualismo do homem atual e suas ganâncias pelo poder e consumismo efêmero, sinaliza o desequilíbrio racional e o afastamento efetivo de uma socialização consolidada. Os vínculos afetivos estão se escasseando à proporção que o sujeito vai descobrindo outros espaços, mesmo que sejam provisórios, até porque o sujeito contemporâneo está condicionado ao desejo de possuir e saciar suas vontades pessoais. A tecnologia de ponta tem sido uma parceira incondicional do sujeito moderno nos dias atuais, possibilitando caminhos favoráveis ao desenvolvimento científico, mas muitas vezes afastando-o do seio afetivo social. De modo que a expansão tecnológica tem contribuído imensuravelmente com a sua formação, porém suas consequências têm sido motivo de preocupação em todo o planeta. O calor humano do sujeito moderno parece esvair-se, paulatinamente, conduzindo os relacionamentos afetivos para terrenos desérticos.

Palavras-Chave: Sujeito, Formação, Sociedade, Globalização.

\footnotetext{
${ }^{1}$ Formado em Normal Superior pela UESPI (Universidade Estadual do Piauí), Pósgraduado em Supervisão Escolar pela Faculdade de Teologia Hokemãh - Fateh e Mestrando em Educação pela Anne Sullivan University.
} 


\section{INTRODUÇÃO}

A constante busca pelo conhecimento científico passou a ser um grande diferencial na formação do sujeito moderno, atualmente. $O$ aperfeiçoamento intelectual sinaliza ser um requisito básico e imprescindível para qualquer indivíduo que almeja manter ou alterar o seu nível de empregabilidade e profissionalismo no mercado que vem exigindo, dia-após-dia, a sua atualização. Cabe, portanto, as instituições educacionais contribuírem para o crescimento evolutivo sem, no entanto, apenas preparar os cidadãos para a vida, uma vez que elas são as próprias vidas. (ALARCÃO, 2001)

Contudo, essas instituições de ensino devem sim, estabelecerem políticas norteadoras e coerentes no estudo de situações reais, capazes de contribuir com a melhoria da formação do sujeito que vivencia uma modernidade repleta de opções e disparidades. Nesse caminho, atuar isoladamente seria um desperdício, tendo em vista, que as ações coletivas são as que probabilizam a efetivação dos melhores resultados.

Admite-se que houve grandes mudanças nos últimos anos no processo da formação do sujeito, mudanças que carecem de reflexão para uma posterior ação positiva com almejos de resultados íntegros e jamais fragmentados ou dissociados da realidade, que sinalizem comprometimento para o enfrentamento do processo globalizado. A escola deve, mais do que nunca, estar imbuída em preparar cidadãos e não somente para desenvolver suas qualidades, mas para contribuir com o equilíbrio da vida na sociedade a qual pertence, exercitando sua função, diagnosticando os principais problemas e apontando soluções.

De modo que o crescimento evolutivo vem exigindo dos profissionais de todos os setores a atualização em seus conhecimentos, uma vez que não basta a sua formação inicial para o resto da vida. A modernidade exige maior comprometimento dos sujeitos para a efetivação de um futuro sólido e sem riscos de desmoronamento social. 


\section{A FORMAÇÃO DO SUJEITO MODERNO}

A escola comprometida com a formação do sujeito moderno é a que está imbuída à realidade dos seus educandos, estabelecendo sempre uma relação recíproca entre teoria e prática de forma flexibilizada, inovadora e crítica, dando ênfase o constante processo de atualização dos seus profissionais. É óbvio que ainda não se alcançou as metas almejadas e direcionadas inteiramente a integração da consciência.

Todavia, na atualidade o sujeito passou a ser visto como algo definido no centro das grandes estruturas e formações mantenedoras de uma nova sociedade. Inclusive, dois eventos contribuem para ampliar os fundamentos conceptuais do sujeito moderno: a biologia de Charles Darwin, onde a razão baseava-se na natureza e a mente no desenvolvimento do cérebro e o aparecimento das ciências sociais.

Admite-se que o ponto inicial dos tempos modernos do sujeito é o seu próprio nascimento que traz como consequências a formação de uma nova mentalidade para a sociedade a que vai ser inserido. O contato com as novas tecnologias que thes são necessárias e imprescindíveis operam mudanças radicais no sujeito de acordo com a época que ele vivencia.

O sujeito moderno é o protagonista da nova sociedade, das novas invenções e das transformações, sendo responsável pela coisificação humana e pelas sequelas resultantes da tecnologia em avanço, tornando o processo cultural desumanizador, individualista, egocentrista e condicionados a reproduzirem a essência da indústria e do entretenimento.

A formação na modernidade está muito mais voltada à estética do ser humano, uma vez que no sistema capitalístico o corpo é comercializado como força de trabalho, ou seja, passa a ser percebido como objeto ou coisa de consumo e riqueza. Nesse contexto as relações interpessoais evadem-se dando lugar a robotização insensível e desumanizadora. No entanto, não se pode pensar na formação do sujeito moderno sem recapitular a vida nos centros urbanos onde há uma incessante luta pelo espaço e a presença da exclusão social, inclusive com altos índices de criminalidade e o 
reinado da violência esmagadora. Não hibridizam as suas culturas, nem tampouco estreitam as suas relações e nem levam em consideração a tolerância.

Nessas circunstâncias a apresentação do sujeito moderno apresenta uma intensa rede de estímulos nervosos podendo afetar suas relações sociais e os níveis de afetividades com a família. De modo que o sujeito da hodierneidade tende a ter um relacionamento indiferente com as pessoas que integram seu grupo afetivo, desconhecendo os vínculos sociais, fraquejando a sua capacidade crítica e deixando de dar importância às suas ações no grupo a que pertence, comprometendo, assim, suas iniciativas pessoais que poderiam contribuir, e muito, na solução dos problemas sociais com a comunidade a que vivencia.

\section{O SUJEITO MODERNO E A GLOBALIZAÇÃO}

Entende-se que o sujeito moderno encontra-se influenciado pelo multiculturalismo em um mesmo espaço geográfico onde a tolerância passa a ser imprescindível na cooperação entre grupos de indivíduos. Apesar da politização da sociedade moderna e demonstração de grande preocupação com o bem estar de cada indivíduo, infelizmente, as diferenças ainda permeiam no dia-a-dia das civilizações, empecilhando a interligação humana.

Vivencia-se uma globalização que avança assustadoramente tanto nas áreas científicas quanto tecnológicas, onde a ciência surpreende, cada vez mais, a sociedade. Cabe ao sujeito a fomentação pelo aperfeiçoamento científico nas especificidades que lhe conferirão a autêntica cidadania mundial. Em hipótese alguma poderia haver desenvolvimento social se o sujeito não se atentar à evolução do conhecimento, uma vez que a tecnologia passou a fazer parte na vida das pessoas, estreitando a inter-relação entre os países no planeta.

Os eventos de alegria e de tristeza, atualmente, une as pessoas em um sentimento global de solidariedade que era desconhecido das gerações anteriores. De outro lado, cada catástrofe, apesar de parecer bastante distante da esfera dos negócios de cada 
um, acaba, em realidade, a repercutir na vida privada de cada um. (Érik Jaime, 2006, p. 51 )

A evolução tem se expandido bastante na formação do sujeito, mas as suas consequências tem sido motivos de preocupação em todo o mundo. A alteração climática e as catástrofes são sinônimos dessas consequências que, silenciosamente, vão consumindo ou degradando a sociedade.

A sociedade hodierna é a do conhecimento, da tecnologia, do egocentrismo, das classes organizadas e do capitalismo, onde o sujeito moderno porta de sua própria liberdade com seu respectivo preço e conhecimento. A sociedade capitalista viabiliza benefícios, contudo requer estudo, tempo e poder, onde o sujeito procura ser totalmente livre, fomentado por status e muito dinheiro para saciar as suas necessidades pessoais, tendo como característica principal o conhecimento, porque isento dele, ficaria excluído da sociedade.

Notadamente, o desenvolvimento da sociedade moderna apresenta aspectos positivos e negativos ao mesmo tempo. Considera-se aspectos aceitáveis a interligação socioeconômica de milhares de pessoas, o fluxo comercial entre continentes, além de outros, tendo como consequências negativas o surgimento das desigualdades sociais, a dispersão de culturas e a fragmentação humanística, ou seja, com a globalização surgiu um observável estreitamento na relação mútua entre povos e nações, dando ênfase o individualismo. Nos últimos anos o multiculturalismo apresentou uma dimensão muito maior entre as sociedades do planeta e dentro dessa consolidação o sujeito moderno passou a aceitar e a compreender os direitos dos diferentes.

\section{A IDENTIDADE E A DIFERENÇA DO SUJEITO MODERNO}

A identidade e a formação do sujeito moderno tem sido fragmentada pelo fenômeno globalização devido o multiculturalismo que trouxe uma série de desentendimentos entre grupos. Ao formar a sua própria identidade, o sujeito termina sendo influenciado por culturas diferentes, criando assim, uma identidade híbrida. 
O processo de formação da identidade oscila entre dois movimentos: de um lado, estão aqueles processos que tendem a fixar e a estabilizar a identidade; de outro lado, os processos que tendem a subvertê-la e a desestabilizá-la. (Tomaz Tadeu da Silva, 2007, p. 84)

Há muito tempo já existia o fenômeno da influência cultural, tanto na formação quanto no comportamento dos sujeitos modernos. De modo que a identidade do sujeito moderno evolui-se constantemente, tornando-se flexível em alguns comportamentos.

O sistema de comunicação globalizado hodierno propõe novos desafios às populações democráticas, resultando nas diferenças étnicas, raciais, religiosas e os constantes fluxos migratórios que, de certa forma, desafiam a sociologia e as ciências afins, desencadeando um entrave para a realização da cidadania nas sociedades multiculturais, levando em conta que o meio do qual o indivíduo faz parte é absolutamente influente em suas vidas.

Estamos entregues a essa grande compulsão que se instala de maneira globalizante, estamos cegos para olhar para nós mesmos e ao outro, substituindo relações por vícios, trabalho desenfreado e cacarecos pós modernos, aumentando a sensação de impaciência em relação ao outro. (CARVALHO, Campos, 2010, p. 4)

Está absolutamente explícito o excesso de celebridades efêmeras, no período da modernidade. Tudo acontece dentro do imediatismo, conduzindo, a galopes, a canseira e o sofrimento psíquico. De modo que, o que realmente identifica o sujeito moderno é a tenra agitação, os cenários violentos e descontrolados e um consumismo espantoso. Tudo parece ter virado vício ilimitado, pois a transformação vem acontecendo com uma rapidez imensurável, onde o poder e o prazer emanam-se.

Por ser promovido pelo consumismo, o sujeito moderno vive com a sua formação comprometida e estressada, gerando, assim, novas modalidades e formas de perceber e agir no mundo em que vive. A felicidade do homem moderno caracterizase com as coisas fictícias e a satisfação imediata, mesmo que as consequências sinalizem fortes amargores. 


\section{AS CONSEQUÊNCIAS DO MODERNISMO}

Considera-se que as novas gerações são verdadeiras manipuladoras da racionalidade, das classes dominantes e da vida capitalista. $O$ individualismo opta pelo artifício e por coisas meramente ilusivas, cujos almejos são os grandes lucros e o poder absoluto, ficando excluídos aqueles que não se capacitarem a fazer parte desse mercado auto regulador da sociedade.

Para Poletto, 1999, esses agentes do mercado globalizado recebem ofertas de todas as fórmulas e de todos os incentivos, no entanto, para os excluídos nenhuma proteção ou oportunidade de liberdade. Até mesmo as inter-relações parecem estar moldadas aos produtos de consumo. A liberdade do povo está entrelaçada à perfeição e a uma série de desejos insignificantes, cujos efeitos são consequências desestabilizadoras.

As transformações produzidas pelo sujeito moderno vem afetando não somente no seu modo de vida, mas também na sua formação, em suas relações sociais e nos vínculos afetivos. O comodismo caracteriza o homem moderno quando ele deixa de pensar à aceitar ideias contemporâneas chegando, muitas vezes, ao fracasso de algumas ideologias clássicas. Ele prefere viver a felicidade passageira, mesmo custando preços muito altos, nem que seja o seu último sonho.

Enfim, o sujeito contemporâneo está condicionado ao desejo de possuir e consumir desmedidamente os melhores bens e chegar aos mais altos status invejados pela sociedade. Já não consome por necessidade, mas por um vício intolerante que o maquia e o deixa feliz. Certos desejos são transgressores, aqueles que partem de grupos criminosos e, ilicitamente, enraízam em atividades altamente sustentáveis e do lucro fácil.

\section{CONSIDERAÇÕES FINAIS}

De certo modo, conclui-se que o sujeito da hodierneidade faz parte de uma sociedade faminta por poderes, com influências vorazes nas questões sociais, onde os resultados consequentes refletem em dilemas que uma sociedade equilibrada não 
gostaria de tê-los. Um projeto moderno que apresenta falhos e desequilíbrios, que privilegiam o consumo e o capitalismo, não serve para uma sociedade que almeja à justiça e a igualdade social.

Há uma necessidade gritante de se lutar pelas estabilidades sociais, onde o sujeito possa ter acesso à própria rédea e não se deixar levar pelas emoções ou pelas armadilhas da modernidade. É necessário que os leques da liberdade sejam acionados contra as conservas sociais e os apelos consumistas.

O uso democrático e legítimo do prazer só poderá ser vivenciado plenamente a partir do momento em que sujeito e sociedade tornarem-se espontâneos, conscientes e a apregoação do amor e do respeito pelos outros forem efetivados. $O$ homem moderno precisa resgatar a sua criatividade e espontaneidade, uma vez que são suas, naturalmente, mas encontram-se obstruídas por todos os tipos de pressão impregnadas pelo sistema social capitalista.

É observável que a modernidade esquiva-se de um projeto emancipativo do sujeito, rompendo vínculos e compromissos sólidos, pois o sujeito vive enredado às suas consequências perversas no dia-a-dia na sociedade. A luta do homem moderno, por consumir algo capaz de saciar suas vontades efêmeras, além de afetar na sua formação psicossocial, gera 0 isolamento do raciocínio lógico e de projetos duradouros que pudessem beneficiar a coletividade. Os avanços tecnológicos neutralizaram boa parte da humanidade moderna na sua forma de socialização, pois o diálogo direto e pessoal está sendo substituído pelo on-line.

\section{REFERÊNCIAS}

BAUMAN, Zygmunt. Vida Líquida. Rio de Janeiro: Jorge Zahar Ed, 2007.

CARVALHO CAMPOS, Maria das Graças de. Axiodrama 654 - uma possibilidade de ressignificar o tempo e a impaciência na pós-modernidade.

GONÇALVES, Maria Augusta Salim. Sentir, pensar, agir: corporeidade e educação. Campinas: Papirus, 1994. 
GRAMSCI, Antônio. Os intelectuais e a organização da cultura. Rio de Janeiro: Civilização Brasileira, 1968.

LIPOVETSKY, Gilles. Los tempos hipermodernos. Traduzido por Antônio Prometeo Moya. Barcelona: Editorial Anagrama, 2006.

MORENO, J. L. Psicoterapia de grupo e Psicodrama. São Paulo, Mestre lou, 1974. MORIN, Edgar. Cultura de massas no século XX. Vol. 1: Neurose. Rio de Janeiro: Forense Universitário, 1974.

POLETTO, Ivo. Vozes do Campo e da Cidade. In:

SILVA, Gidati Guedes. Modernidade, Cultura e Formação do Sujeito

SIMMEL, Sigmund George. A metrópole e a vida mental. Rio de Janeiro: Guanabara, 1987. 